Yibin Zhang* and Lei Shi

\title{
Retraction of: Concentrating solutions for a planar elliptic problem with large nonlinear exponent and Robin boundary condition
}

https://doi.org/10.1515/anona-2017-5001

Retraction of:

Y. Zhang and L. Shi. Concentrating solutions for a planar elliptic problem with large nonlinear exponent and Robin boundary condition. Online publication: 19 April 2016. DOI: 10.1515/anona-2015-015310.1515/anona2015-0153.

The Editors have requested that the article be withdrawn due to prior publication.

*Corresponding Author: Yibin Zhang, College of Sciences, Nanjing Agricultural University, Nanjing 210095, P. R. China, E-mail: yibin10201029@njau.edu.cn 